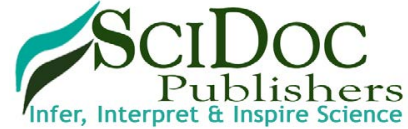

International Journal of Reproduction, Fertility \& Sexual Health (IJRFSH) ISSN: $2377-1887$

\title{
The Effective Factors on Time to Pregnancy In Reproductive Age Women, West of Iran
}

Research Article

\author{
Heydarpour $\mathrm{F}^{1}$, Heydarpour $\mathrm{S}^{2}$, Najafi $\mathrm{F}^{3}$, Holakouie-Naieni $\mathrm{K}^{* 4}$
}

${ }^{1}$ Emam Ali Hospital, Kermanshah University of Medical Sciences, Kermanshah, Iran.

${ }^{2}$ Department of Midwifery, Kermanshah university of Medical sciences, Kermanshah, Iran.

${ }^{3}$ Associate Professor, Department of Epidemiology and Biostatistics, school of public Health, Kermanshah university of Medical sciences,

Kermanshah, Iran.

${ }^{4}$ Professor, Department of Epidemiology and Biostatistics, school of public Health, Tehran university of Medical sciences, Tehran, Iran.

\section{Abstract}

Background: The time required to achieve the pregnancy is called time to pregnancy (TTP). The effective factors on TTP are different because of the different life style and geographical condition in various countries. The present study aimed to determine the effective factors on TTP in Kermanshah in 2010.

Method: In this case-control study, 174 mothers with TTP $\geq 12$ months and 587 mothers with TTP $<12$ months were selected as case and control group, respectively. A questionnaire was used for data collection. The data were analyzed by SPSS, V.16 software and $\mathrm{p}<0.05$ was considered as significance level.

Results: Based on the results of Multi-variant analysis, women education level (Diploma and higher)( OR-0.854, CI 95\% $=0.741-0.984)$, increasing intercourse frequency per week $(\mathrm{OR}=0.728$, CI 95\% $=0.631-0.839)$, not exposure to smoking $(\mathrm{OR}=0.606$, CI $95 \%=0.380-0.965)$ and blood group A compared to $\mathrm{O}(\mathrm{OR}=0.639$, CI $95 \%=0.405-1.01)$ significantly reduced TTP. Some factors as BMI $>25 \mathrm{~kg} / \mathrm{m}^{2}(\mathrm{OR}=2.221$, CI $95 \%=1.489-3.312)$, irregular menstrual $(\mathrm{OR}=3.70$, CI $95 \%=2.127-6.441)$ and the lack of doing sport activities among females $(\mathrm{OR}=1.920, \mathrm{CI} 95 \%=1.263-2.918)$ increased TTP.

Conclusion: Based on the results of this study, some factors as high BMI and the lack of doing sport activities increased TTP and some factors as increasing the intercourse frequency per week reduced its chance. The couples who plan for pregnancy and follow medical interventions don't consider the factors of TTP. It is recommended that health care staffs support the couples and give them the required consultations.

Keywords: Time to Pregnancy (TTP), Age, Subfertility, Effective Factors, Kermanshah.

\section{Introduction}

The time required to achieve the pregnancy is called time to pregnancy (TTP). TTP was used to measure fertility and evaluate fertility outcomes since 1980 [1, 2]. If despite frequent unprotected intercourses, TTP takes more than 12 months, it is defined sub fertility [3]. The prevalence of TTP $>12$ months was reported in some countries including Denmark (13\%), England (18.8\%), South of Italy (16\%), Eastern Germany (24\%) and Tabriz (Northwest of Iran) (17.5\%) [2-4]. Personal differences and life style play crucial role in subfertility $[5,6]$. Some factors as using alcohol, full-time job, taking oral contraceptive before pregnancy, night shift and stress, menstrual cycle duration, gestational age and parity were associated with TTP [7]. However, Zilaitiene et al., didn't found any significant association between previous use of oral contraceptive, regular menstrual cycle, gestational age, intercourse frequency and TTP [8]. The factors related to life style including using alcohol $[7,9]$ and smoking $[7,8,10,11]$ affect fertility via postponing pregnancy and increasing miscarriage risk. Alderet et al., performed a study on the association between smoking and coffee and TTP, they found a significant relation between smoking and TTP [10]. Stress disturbs menstrual performance and re-

*Corresponding Author:

Kourosh Holakouie-Naieni Ph,D,

School of Public Health and Institute of Public Health Research (SPH \& IPHR) Tehran University of Medical Sciences (TUMS) P.O.Bo, Iran.

Tel: 0098-21-88989122

Fax: 0098-21-88989127

E-mail: Holakoin@sina. tums.ac.ir ; holakoik@hotmail.com

Received: August 08, 2016

Accepted: September 09, 2016

Published: September 17, 2016

Citation: Heydarpour F, Heydarpour S, Najafi F, Holakouie-Naieni K* (2016) The Effective Factors on Time To Pregnancy in Reproductive Age Women, West of Iran. Int J Reprod Fertil Sex Health. 3(4), 79-85. doi: http://dx.doi.org/10.19070/2377-1887-1600014

Copyright: Holakouie-Naieni $\mathbf{K}^{\circ}$ 2016. This is an open-access article distributed under the terms of the Creative Commons Attribution License, which permits unrestricted use, distribution and reproduction in any medium, provided the original author and source are credited. 
duces fertility and increases miscarriage risk. In addition, it seems that job relate factors including the number of working hours, prolonged standing and night shift affect women fertility system and fetus growth [7]. The results of the study performed by Hjollund et al didn't support the hypothesis of the harmful effect of work pressure on fertility [12]. Spinelii et al., didn't report any association between job exposures of women and prolonged TTP. While men job in the industry and exposure to welding foams was associated with increase of TTP [11]. In a study, the women carrying the loads $\geq 5 \mathrm{~kg}$ had better pregnancy outcome [13]. However, in some populations, prolonged TTP was associated with more physical activity [14]. Some of the studies showed that exposure to agriculture pesticides led into subfertility in women $[13,15]$. In other studies, there was no significant association between exposure to pesticides and TTP [10]. The results of the studies regarding the relation of blood group $\mathrm{ABO}$ system and infertility are contradictory $[16,17]$. In some studies, BMI (Body Mass Index) was associated with subfertility [18]. The studies in European countries showed that geographical condition played important role in couples' fertility [19]. One of the main objectives of initial health care is prevention as economical and effective strategy to cope with the medical problems including subfertility problems. The recommendations based on evidences of general physicians can lead into dramatic reduction in attendance of patients for medical interventions [3]. About $80 \%$ of the couples who don't get pregnant, follow treatment, while $70 \%$ of them get pregnant after 2 years without any medical intervention [4]. The effective factors on TTP are different because of the different life style and geographical condition in various countries. For example, some factors as smoking and drinking alcohol and coffee are most common in various countries compared to our country. Based on the contradiction of the results of the studies regarding the factors of subfertility and the studies, it is found that geographical condition influenced couples fertility. The current study aimed to determine the effective factors on TTP in Kermanshah.

\section{Materials and Methods}

In the current analytical design (case-control) study, the sample size was calculated based on difference in pilot for first degree error of $\alpha=0.05$, second degree error of $\beta=10 \%(90 \%)$ and the ratio of 1 to 3 for case and control by PS software (precise and sample size calculations. version 3.0. 34. January 2009). The required sample was determined for study variables and maximum sample was dedicated to drinking tea ( 6 cups and more) (124 cases and $124 * 3$ control). To achieve the sample size, the duration to collect the samples, the mothers attending one of the hospitals of Kermanshah in maternity ward was estimated 8 weeks. Fortunately, more samples were collected. To make the sample size consistent with the population covered by these hospitals, concurrent sampling was started in these centers and finished. A written consent form was completed for all the subjects. The inclusion criteria were first or second pregnancy, planned pregnancy, and good condition of mother and inclination of mother to attend the study. In the current study, TTP was used to measure fertility and the women with TTP 12 months were selected as case group and the mothers with TTP $<12$ months were control group. In this study, to reduce recall bias, the first or second pregnancy women were used in the study. The data collection instrument was a two-section questionnaire. The first section was consisting of 53 questions for the data of women; the second question was including 15 ques- tions about the data of spouse (male). To measure the economical status, floor space per capita (national plan of a survey on health and disease in Iran, 1999) was applied. To determine the scientific validity of questionnaire, content validity was used. The questionnaire was distributed to10 faculty members of nursery, midwifery and medicine school of Kermanshah and it was proved after presenting the comments. To determine the scientific reliability of the questionnaire, test-posttest was used. Spearman test showed that test-posttest scores were related considerably to each other. For data collection, the students interested in midwifery research of nursery-midwifery school of Kermanshah being familiar with the study structure in a session were applied and they were blind to the main hypothesis. The sampling took 2 months and the data were analyzed by SPSS version 16 software. To test quantity variables, after the investigation of the normality, the variables were tested by Kolmogorov-Smirnov and t-test was used in cased of insignificance of test and non-parametric test (Mann-Whitney test) test was used in cased of significance of the test. To test quality variables, chi-square test was applied. Finally, logistic regression and backward methods were used. The data analysis was conducted by SPSS software. Error level less than 0.05 was considered as significance level.

\section{Results}

In this study, 761 women with planned pregnancy were included in the study. 174 women $(22.9 \%)$ with TTP $\geq 12$ months were selected as case group and 587 mothers $(77.1 \%)$ with TTP $<12$ months were selected as control group. The mean age of women in case and control group was $29.3 \pm 5.54$ and $26 \pm 4.68$ years, respectively and the age mean of their spouse was $34.2 \pm 6.54$ and $30.5 \pm 5.53$, respectively. Frequency and percent of quality variables and mean and standard deviation of quantity variables effective on TTP in case and control group were shown in Table 1, respectively. Based on the results of this study, there was a significant difference between education level of women, regular menstrual, subfertility and infertility family history, fertility related diseases among men and women, history of twin pregnancy, stillbirth, smoking among men and women, sport activities of women, using Jacuzzi, bathtub and hot water ponds among men, BMI before pregnancy of women, alcohol use among men, using non-alcoholic drinking among women, using 6 cups of tea per day, the intercourse frequency between case and control groups and exposure to smoking among women in mono-variant analysis. However, the results of multi-variant analysis showed that menstrual irregularity, BMI $>25 \mathrm{~kg} / \mathrm{m}^{2}$, the history of infertility diseases of men and women and the lack of sport activities of women significantly increased TTP. Some variables as increasing the intercourse frequency per week, women education level (Diploma and higher), blood group A compared to blood group $\mathrm{O}$ and not exposure to smoking reduced TTP (Table 2).

\section{Discussion}

TThe current study showed that some factors affect TTP. After using multi-variant analysis, the factors including menstrual irregularity, BMI $>25 \mathrm{~kg} / \mathrm{m}^{2}$, the history of infertility diseases of men and women and the lack of sport activities of women significantly increased TTP and some factors as increasing intercourse frequency per week, blood group A compared to $\mathrm{O}$, high education level of women (Diploma and higher) and the lack of expo- 
Table 1. Uni-variant analysis of the effective factors on TTP

\begin{tabular}{|c|c|c|c|c|c|}
\hline \multirow[t]{2}{*}{ Life style and biologic factors } & \multicolumn{2}{|c|}{ Control } & \multicolumn{2}{|c|}{ Case } & \multirow[t]{2}{*}{ P-value } \\
\hline & $\mathrm{N}$ & $\%$ & $\mathrm{~N}$ & $\%$ & \\
\hline \multicolumn{6}{|l|}{ Female education } \\
\hline Not graduate from high school & 226 & 38.5 & 83 & 47.7 & \multirow{3}{*}{0.030} \\
\hline Graduate from high school and upper & 361 & 61.5 & 91 & 52.3 & \\
\hline Total & 587 & 100 & 174 & 100 & \\
\hline \multicolumn{6}{|l|}{ Male education } \\
\hline Not graduate from high school & 211 & 35.9 & 60 & 34.5 & \multirow{3}{*}{0.723} \\
\hline Graduate from high school and upper & 376 & 64.1 & 114 & 65.5 & \\
\hline Total & 587 & 100 & 174 & 100 & \\
\hline \multicolumn{6}{|l|}{ Male job } \\
\hline $\begin{array}{l}\text { Jobs with long time standing or pesticides ex- } \\
\text { posure }\end{array}$ & 381 & 65 & 113 & 64.9 & \multirow{3}{*}{0.986} \\
\hline Jobs without long time standing & 205 & 35 & 61 & 35.1 & \\
\hline Total & 586 & 100 & 174 & 100 & \\
\hline \multicolumn{6}{|l|}{ Socioeconomic status } \\
\hline Weak & 85 & 15.6 & 21 & 13.2 & \multirow{4}{*}{0.4} \\
\hline Average & 266 & 48.8 & 73 & 45.6 & \\
\hline Good & 194 & 35.6 & 66 & 41.2 & \\
\hline Total & 545 & 100 & 160 & 100 & \\
\hline \multicolumn{6}{|l|}{ Male smoking } \\
\hline Yes & 100 & 17 & 50 & 28.7 & \multirow{3}{*}{0.001} \\
\hline No & 487 & 83 & 124 & 71.3 & \\
\hline Total & 587 & 100 & 174 & 100 & \\
\hline \multicolumn{6}{|l|}{ Female exercise doing } \\
\hline Yes & 283 & 48.2 & 60 & 34.5 & \multirow{3}{*}{0.001} \\
\hline No & 304 & 51.8 & 114 & 65.5 & \\
\hline Total & 587 & 100 & 174 & 100 & \\
\hline \multicolumn{6}{|l|}{ Male exercise doing } \\
\hline Yes & 284 & 48.5 & 74 & 42.5 & \multirow{3}{*}{0.168} \\
\hline No & 302 & 51.5 & 100 & 57.5 & \\
\hline Total & 586 & 100 & 174 & 100 & \\
\hline \multicolumn{6}{|l|}{$\begin{array}{l}\text { Use of oral contraceptive before deciding to } \\
\text { pregnancy }\end{array}$} \\
\hline Yes & 177 & 30.2 & 48 & 27.6 & \multirow{3}{*}{0.515} \\
\hline No & 410 & 69.8 & 126 & 72.4 & \\
\hline Total & 587 & 100 & 174 & 100 & \\
\hline \multicolumn{6}{|l|}{ Use of Jacuzzi and hot water pool by men } \\
\hline Yes & 14 & 2.4 & 20 & 11.5 & \\
\hline No & 572 & 97.6 & 154 & 88.5 & $<0.001$ \\
\hline Total & 586 & 100 & 174 & 100 & \\
\hline Female BMI before deciding to pregnancy & & & & & \\
\hline$<=25 \mathrm{~kg} / \mathrm{m}^{2}$ & 427 & 73.4 & 92 & 53.2 & \\
\hline$>25 \mathrm{~kg} / \mathrm{m}^{2}$ & 155 & 26.6 & 81 & 46.8 & $<0.001$ \\
\hline Total & 582 & 100 & 173 & 100 & \\
\hline Male alcohol consumption & & & & & \\
\hline Yes & 21 & 3.6 & 14 & 8 & \\
\hline No & 566 & 96.4 & 160 & 92 & 0.013 \\
\hline Total & 587 & 100 & 174 & 100 & \\
\hline Female non- alcoholic beverages consumption & & & & & \\
\hline Yes & 276 & 47 & 98 & 56.3 & \\
\hline No & 311 & 53 & 76 & 43.7 & 0.031 \\
\hline Total & 587 & 100 & 174 & 100 & \\
\hline
\end{tabular}




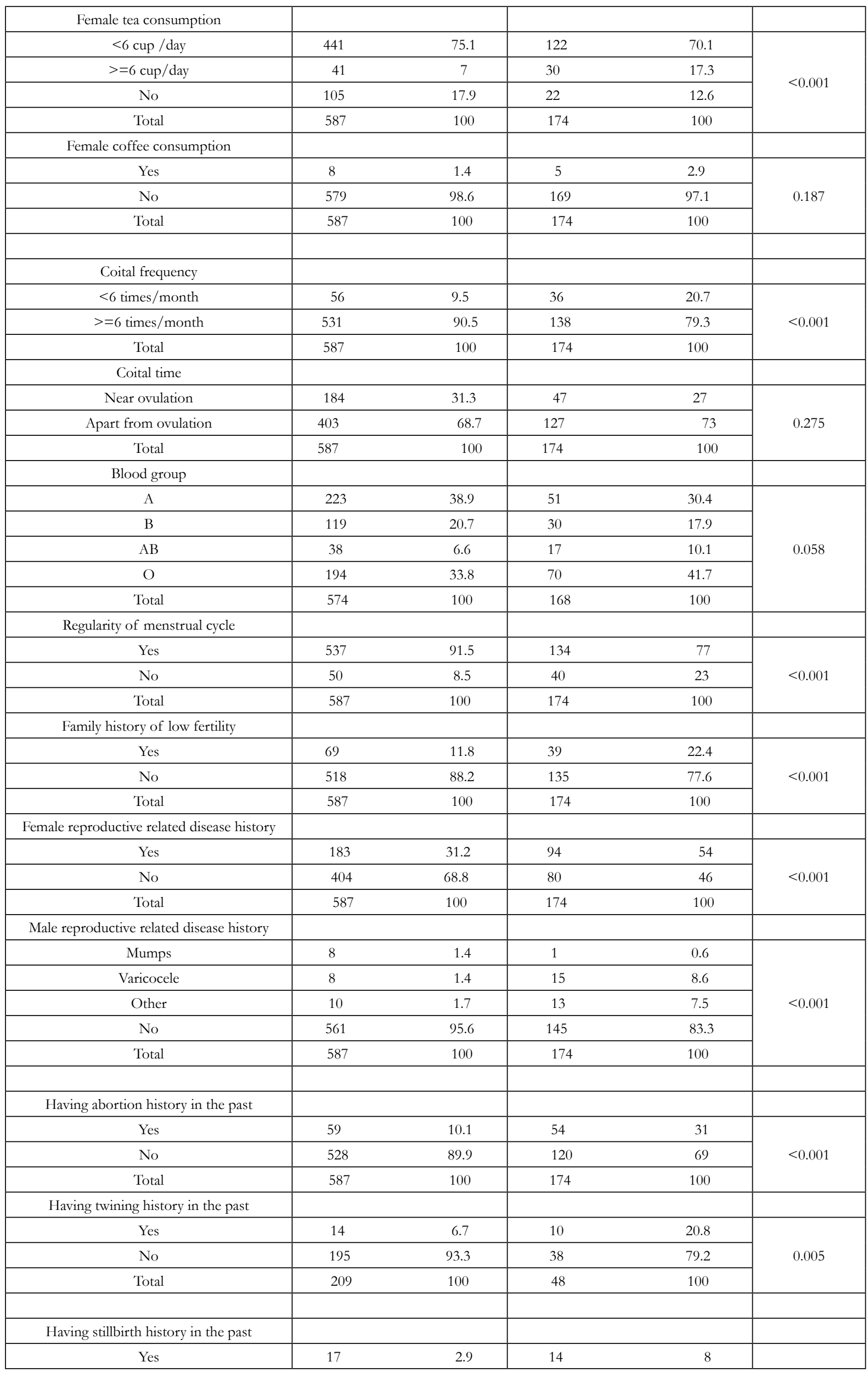




\begin{tabular}{|c|c|c|c|c|c|c|c|}
\hline No & \multirow{2}{*}{\multicolumn{2}{|c|}{$\begin{array}{l}570 \\
587\end{array}$}} & 97.1 & \multirow{2}{*}{\multicolumn{2}{|c|}{$\begin{array}{c}160 \\
174\end{array}$}} & \multirow{2}{*}{$\begin{array}{l}92 \\
100\end{array}$} & \multirow{2}{*}{0.003} \\
\hline Total & & & 100 & & & & \\
\hline \multicolumn{8}{|l|}{ Female Passive smoking } \\
\hline Yes & 107 & & 18.2 & & & & \multirow{2}{*}{0.007} \\
\hline No & 480 & & 81.8 & & & & \\
\hline Total & 587 & & 100 & & & & \\
\hline \multirow[t]{2}{*}{ Female age at deciding time for pregnancy } & $\mathrm{N}$ & Mean & SD & $\mathrm{N}$ & Mean & SD & \multirow{2}{*}{0.746} \\
\hline & 587 & 25 & 4.693 & 174 & 25.3 & 6.019 & \\
\hline male age at deciding time for pregnancy & 587 & 29.5 & 5.587 & 174 & 30.4 & 6.861 & 0.746 \\
\hline Female marriage's age & 587 & 21.4 & 4.190 & 174 & 21.3 & 5.407 & 0.324 \\
\hline Male marriage's age & 587 & 26 & 4.861 & 174 & 26.3 & 5.982 & 0.926 \\
\hline Male working hours/week & 539 & 52.6 & 13.39 & 167 & 54.9 & 13.096 & 0.96 \\
\hline
\end{tabular}

Table 2. Multi-variant analysis of the effective factors on TTP

\begin{tabular}{|c|c|c|c|c|}
\hline Factors & P-value & OR & $95 \%$ & CI \\
\hline \multicolumn{5}{|l|}{ Female education } \\
\hline Graduate from high school and upper & 0.028 & 0.854 & 0.741 & 0.984 \\
\hline Increase the number of coital in week & $<0.001$ & 0.728 & 0.631 & 0.839 \\
\hline Lack of passive exposure & 0.035 & 0.606 & 0.380 & 0.965 \\
\hline Lack of Female disease history & 0.001 & 0.520 & 0.350 & 0.774 \\
\hline \multicolumn{5}{|l|}{ Blood group } \\
\hline A & 0.055 & 0.639 & 0.405 & 1.010 \\
\hline B & 0.081 & 0.608 & 0.348 & 1.062 \\
\hline $\mathrm{AB}$ & 0.149 & 1.692 & 0.828 & 3.460 \\
\hline $\mathrm{O}$ & & 1 & & \\
\hline Irregular menstruation & $<0.001$ & 3.701 & 2.127 & 6.441 \\
\hline Female lack of exercise doing & 0.002 & 1.920 & 1.263 & 2.918 \\
\hline $\mathrm{BMI}>=25 \mathrm{~kg} / \mathrm{m}^{2}$ & $<0.001$ & 2.221 & 1.489 & 3.312 \\
\hline \multicolumn{5}{|l|}{ Male related disease and reproductive history } \\
\hline Mumps & 0.546 & 0.517 & 0.061 & 4.394 \\
\hline Varicocele & $<0.001$ & 6.792 & 2.600 & 17.739 \\
\hline Other & $<0.001$ & 6.502 & 2.277 & 18.564 \\
\hline No & & 1 & & \\
\hline
\end{tabular}

sure to smoking decreased prolonged TTP. Fertility is measured by TTP and it is defined that TTP is used to analyze the effective factors on reproductive system [7]. One of the limitations of this study was recall bias. Although it is attempted that by selecting the mothers with first and second pregnancy, this problem is removed. As data collection instrument is questionnaire and based on the memory of the subjects, the bias is possible, there is also the bias of interviewers. It was attempted to be blind to the main hypothesis of the test. In the current study, there was a significant relation between women education and TTP. In other words, by increasing education level, subfertility prevalence is reduced among women. This finding was consistent with the results of previous studies $[4,20]$. The reduction of subfertility among women with high education level is because of low prevalence of the diseases related to fertility, following rapid treatment in case of their disease or their information about their ovulation time. However, in the study performed by Jensen et al. regarding the fertility by TTP in four regions as Paris, Edinburg, Kopenhac and Torko, prolonged TTP was observed in Paris compared to Ed- inburg, Kopenhac and Torko. While the percent of women with academic education in these regions was $73.2 \%, 23.7 \%, 25.4 \%$, $50.5 \%$ respectively. Gensen reported that their information about education didn't include many details. This can be justification of the different result of the above study and current study [21]. The results of the current study showed that BMI $\geq 25 \mathrm{~kg} / \mathrm{m}^{2}$ was consistent with prolonged TTP. In a study performed by Gesink et al, the results showed that obese women had less fertility value compared to the women with normal weight. They found that obesity was associated with reducing fertility [22]. In the study performed by Hassan et al. The influence of BMI on fertility was two-model. It means that in women with high BMI (MBI $>25 \mathrm{~kg} /$ $\mathrm{m}^{2}$ ) and among women with low BMI, the fertility was reduced. In low-weight women, ovulation is reduced and this is an explanation for significant reduction of fertility in these women. In the study performed by Hassan et al. obesity had significant influence on fertility. The influence of obesity on fertility has direct effect, or because of leptin dysfunction as an important factor to control BMI and reproductive system or as the result of polycystic 
ovarian syndrome as a common condition among obese women. Among women with polycystic ovarian syndrome, weight reduction can increase fertility chance and the success of fertility treatments $[3,23]$. Both obesity and low-weight can affect reproductive performance via hormone imbalance and ovary dysfunction [24]. The results of Nohr et al. study showed that both low weight of mother at birth time $(\leq 2500 \mathrm{~g}$ in term infants and $\leq 1500 \mathrm{~g}$ in preterm infants) and high-weight of mother at birth time ( $\geq$ $4500 \mathrm{~g}$ in term infants and $\geq 3500 \mathrm{~g}$ in preterm infants) were associated with risk increase of TTP more than 1 year [2]. The effect of smoking on general health is accepted well. The results of the current study showed that exposure to smoking had significant association with prolonged TTP. Some studies showed the negative influence of smoking on fertility [3, 8]. Smoking in women can affect the follicle and causes hormone dysfunction in luteal phase. Cotinine and cadmium were found in follicular fluid of smoking women and men. Thus, smoking affects follicular evolution [24]. Another study showed that thickness of zona pellucida is increased among smokers and this makes difficult the sperm penetration [25]. A demographic-based study on 13893 pregnant women showed that active or passive smoking among women caused significant delay in pregnancy [26]. In a study performed by Mohammad Poorasl et al., there was no significant relation between TTP and spouse smoking [4]. It seems that the difference of the current study and other studies with the study of Mohammad poorasl was because of non-acceptability of smoking in the sample population, reported smoking less than real, or it is because the women are not exposed to the smoke of their spouse. In the current study, blood group O compared to A was associated with TTP $>12$ months. In a study performed in Japan, when father blood group was $\mathrm{O}$, the fertility was less compared to the cases in which the father or none of the couples had blood group O [27]. In another study performed in China, blood group A was more in infertile women than fertile women [16]. Behrman et al didn't find any significant difference between blood group among fertile and infertile couples [17]. It seems that to prove the findings, more studies are required. In the current study, the intercourse frequency per week had significant difference in both groups. In the study performed by Idrovo et al, prolonged TTP and infrequent intercourse was observed [15]. Also, in the study performed by Spinelli, intercourse frequency $\geq 6$ times per month reduced TTP [11]. However, in the study performed by Zilaitiene, intercourse frequency didn't have significant association with TTP [8]. Hassan et al didn't support the theory that frequent or scheduled intercourse can increase fertility chance and it was in consistent with other studies [3]. This finding is used to answer the common question of couples who want to be pregnant. The results of the study of Hassan et al. showed that the effect of negative factors is collective life method and by increasing negative factors, fertility is reduced. This can be a justification for the difference of the results. In the investigation of menstrual cycle characteristics (start age, regularity and period duration) in both groups, it was found that menstrual regularity in both groups had significant difference that was consistent with the study of Idrovo et al., [15]. However, in the study of Zilaitiene et al., menstrual cycle regularity didn't have significant association with TTP [8]. As menstrual regularity is a sign of ovulation, it seems that fertile women had regular menstrual cycle than subfertile women. Based on the results of the current study, aerobic activity in both groups had significant difference and the women doing aerobics had short TTP. Sport affects general health of an individual and prevents obesity, cardio-vascular diseases, high blood pressure, diabetics, osteoporosis and mental stresses.

Rich-Edwards et al found that sport was associated with reduction of infertility risk because of the lack of ovulation. The researchers after controlling BMI found that one hour serious sport activity reduced the relative risk to 5 percent. This showed that physical activity separated of BMI can be a protective factor in ovaries performance. There was no association between average sport and reducing infertility risk [28]. It seems that sport increased sensitivity to insulin and led into the improvement of ovary performance and increased fertility chance [29]. The current study showed that the history of pregnancy related diseases among women and men significantly increased prolonged TTP. Infertility can be due to many causes including ovulation dysfunction, Tubal disorders, Endometriosis, chromosome anomalies, sperm-related factors and infertility [24]. The studies showed that low progesterone in the mid of Luteal phase (defect of Luteal phase) caused fertility failure. Thus, low level of progesterone is a factor risk to postpone fertility [1]. It is not expected that if the history of fertility related diseases with pregnancy in men and women increased the chance of prolonged TTP.

\section{Conclusion}

Based on the results of the study and multi-variant analysis, menstrual irregularity, BMI $>25 \mathrm{~kg} / \mathrm{m}^{2}$, the history of fertility related diseases among men and women and the lack of sport activities of women increased significantly the chance of prolonged TTP. Some variables as increasing the intercourse frequency per week, blood group A compared to $\mathrm{O}$, high education of women (Diploma and higher) and not being exposed to smoking reduced prolonged TTP. The subfertile couples following medical interventions don't consider life style factors having negative effect on fertility. Improving healthy life style among the couples tending to pregnancy not only is important for general health but also to prevent subfertility. The initial health care system staffs are in unique condition to teach the couples, consult with them and support them [3]. Based on the results of this study, if the couples follow healthy life style, subfertility is reduced and this can lead into the reduction for medical interventions and fertility treatment.

\section{References}

[1]. Axmon A, Hagmar L (2005) Time to pregnancy and pregnancy outcome. Fertil Steril. 84(4): 966-74.

[2]. Nohr EA, Vaeth M, Rasmussen S, Ramlau-Hansen CH, Olsen J (2009) Waiting time to pregnancy according to maternal birth weight and pre-pregnancy BMI. Hum Reprod. 24(1): 226-232.

[3]. Hassan MAM, Killick SR (2004) Negative lifestyle is associated with a significant reduction in fecundity. Fertil Steril. 81(2): 384-92.

[4]. Mohammad poorasl A, Seyyedrasoli A, Rostami F, vahidi R (2007) Time-ToPregnancy in Tabriz's women. Research journal of Biological sciences. 2(4): 454-8.

[5]. Kidd SA, Eskenazi B, Wyrobek AJ (2001) Effects of male age on semen quality and fertility: a review of the literature. Fertil Steril. 75(2): 237-48.

[6]. Bolumer F, Olsen J, Rebag liato M, Saez L, Loret I, et al., (2000) Body mass index and delayed conception: a European multicentre study on infertility and subfecundity. Am J Epidemiol. 151(11): 1072-9.

[7]. Axmon A, Rylander L, Albin M, Hagmar L (2006) Factors affecting time to pregnancy. Hum Reprod. 21(5): 1279-84.

[8]. Zilaitiene B, Dirzauskas M, Preiksa RT, Matulevicius V (2007) Cigarette smoking and waiting time to pregnancy: results of a pilot study. Medicina (Kaunas). 43(12): 959-63.

[9]. Buck Louis GM, Dmochowski J, Lynch C, Kostyniak P, McGuinness BM, et al., (2009) Polychlorinated biphenyl serum concentrations, lifestyle and 
time-to-pregnancy. Hum Reprod. 24(2): 451-8.

[10]. Thonneau P, Abell A, Larsen SB, Bonde JP, Joffe M, et al., (1999) Effects of pesticide exposure on time to pregnancy : results of a multicentre study in france and Denmark. Am J Epidemiol. 150(2): 157-163.

[11]. Spinelli A, Figa-Talamanca I, Osborn J (1997) Time to pregnancy and occupation in a group of Italian women. Int J Epidemiol. 26(3): 601-9.

[12]. Hjollund NH, KoldJensen T, Bonde JP, Henriksen TB, Kolstad HA, et al., (1998) Job strain and time to pregnancy. Scand J Work Environ Health. 24(5): 344-50

[13]. Burdorf A, Brand T, Jaddoe VW, Hofman A, Mackenbach JP, et al., (2011) The effects of work-related maternal risk factors on time to pregnancy, preterm birth and birth weight: the Generation R Study. Occup Environ Med. 68(3): 197-204.

[14]. Folrack EI, Zielhuis GA, Rolland R (1994) The influence of occupational physical activity on the menstrual cycle and fecundability. Epidemiology. 5(1): 14-18.

[15]. Idrovo AJ, Sanin LH, Chavarro J, Caceres H, Narvaez J, et al., (2005) Time to first pregnancy among women working in agricultural production. Int Arch occup Environ Health. 78(6): 493-500.

[16]. Saha N, Ratnam SS (1981) Genetic Association in infertility : ABO, RH(subtypes), Lea Blood groups, G6PD deficiency and haemoglobin types. Singapore Med J. 22(1): 16-19.

[17]. Behrman SJ, Buettner-Janusch J, Heglar R, Gershowitz H, Tew WL (1960) $\mathrm{ABO}(\mathrm{H})$ blood incompatibility as cause of infertility : anew concept. Am J Obstet Gyn. 79: 847-855.

[18]. Wise LA, Rothman KJ, Mikkelsen EM, Sorensen HT, Riis A, et al., (2010) An internet-based prospective study of body size and time-to-pregnancy. Hum Reprod. 25(1): 253-64

[19]. Juul S, Karmaus W, Olsen J, (1999) Regional differences in waiting time to pregnancy: pregnancy-based surveys from Denmark, France, Germany,
Italy and Sweden . The European Infertility and subfecundity study Group. Hum Reprod. 14(5): 1250-4.

[20]. Abediniya N, Ramazanzadeh F, Agsamalek M (2003) The relationship of anxiety and depression with duration of infertility. Payesh. 4: 253-8.

[21]. Jensen TK, Slama R, Ducot B, Suominen J, Cawood EHH, et al., (2001) Regional differences in waiting time to pregnancy among fertile couples from four European cities. Hum Reprod. 16(12): 2697-2704.

[22]. Gesink law DC, Maclehose RF, Longnecker MP (2007) Obesity and time to pregnancy. Hum Reprod. 22(2): 414-20.

[23]. Pasquali R, Casimirri F, VicennatiV (1997) Weight control and its beneficial effect on fertility in women with obesity and polycystic ovary syndrome. Hum Reprod. 12: 82-87.

[24]. Homan GF, Davies M, Norman R (2007) The impact of lifestyle factors on reproductive performance in the general population and those undergoing infertility treatment: a review. Hum Reprod update. 13(3): 209-23.

[25]. Shiloh H, Lahav-Baratz S, Koifman M, Ishai D, Bidder D, et al., (2004) The impact of cigarette smoking on zona pellucidathickness of oocytes and embryos prior to transfer into the uterine cavity. Hum Reprod. 19(1): 157-9.

[26]. Hull MG, North K, Taylor H, Farrow A, Ford WC (2000) Delayed conception and active and passive smoking. The Avon Longitudinal Study of Pregnancy and Childhood Study Team. Fertil Steril 74(4): 725-33.

[27]. Matsunaga E, Itoh S (1957) Blood groups and fertility in a Japanese population, with special reference to intrauterine selection due to maternal foetal incompatibility. Annals of Human Genetics. 22(2): 111-131.

[28]. Rich-Edwards JW, Spiegelman D, Garland M, Hertzmark E, Hunter DJ, et al., (2002) Physicalactivity, body mass index, and ovulatory disorder infertility. Epidemiology. 13(2): 184-190.

[29]. Norman RJ, Clark AM (1998) Obesity and reproductive disorders: a review. Reprod Fertil Dev. 10(1): 55-63. 